\title{
COURSE LINKING IN THE UNDERGRADUATE CURRICULUM AT WESTERN ENGINEERING
}

\author{
Kurowski, P M; Floryan M J \\ Department of Mechanical and Materials Engineering, The University of Western Ontario, Ontario Canada \\ pkurowski@eng.uwo.ca
}

\section{INTRODUCTION}

A well established system of grading is used to verify if the understanding of course based knowledge has been effective. Unfortunately, we have no control over how that piecewise knowledge is amalgamated and what kind of global understanding of engineering students are left with. The relevance of one course to another is established by a system of pre-requisite requirements but this is not sufficient to build bridges between different courses. We also have little control over the overall balance between engineering theory and implementation, because theory is more specific to particular courses while implementation is by nature more multidisciplinary.

To address these problems, an effort is underway to deliver courses in a more unified manner where material of one course is perceived as relevant to other courses and knowledge and tools learned in previous courses are applicable, required and expanded in subsequent courses. Our goal is to obtain a synergistic effect between courses and catalyze the amalgamation of course based knowledge into a unified understanding of the engineering field.

In this paper we present our approach and discuss early results. Most importantly, we invite discussion on this initiative which merits are intuitively obvious but often difficult to quantify and the process itself is difficult to implement.

\section{METHODS}

Most obvious candidates for linking are courses that share a common theme. Often they are already linked by pre-requisite requirements and are taught by instructors who share common interests. Authors have concentrated their efforts on courses with high design content starting with the first year course "Introductory Design and Innovation Studio". This course introduces first year students to design, and all subsequent courses must be linked directly or indirectly to this one. This first year design course introduces three phases of the design process: specifications, concept and detailed design. Design tools used in each phase are not specific to any engineering discipline, the detailed design phase is treated liberally and CAD is only briefly introduced. The course linking process starts with linking the second year Product Design course to the first year course. The second year course is taken by students in the Mechanical and Materials Engineering program. Its outline has been modified to avoid repetitions and overlaps especially in the design methodology introduced in the first year course. This made time available to focus on detailed design which was impossible in the first year course, both because of time constraints and because the first year course was not mechanical engineering specific. The second year course covers advanced CAD and topics such as Design for Assembly, Design for Manufacturing, DFMA etc. From students' perspectives, $\mathrm{CAD}$, in this case implemented with SolidWorks, is the most visible connection between the first and the second year design courses. In the second year design course students are given an opportunity to obtain SolidWorks certification as a bonus. An average of $50 \%$ of classes pass the certification exam and majority of students becomes proficient in using $\mathrm{CAD}$ for modeling and detailed design including engineering drawings and documentation. Course deliverables are industrial quality design reports and documentation which are prepared under guidelines and with help of technicians from University Machine Services. Good knowledge of CAD forms a stepping stone to several third year courses while skills in design documentation feed the internship programs after third year.

In third year course on Finite Element Analysis (FEA), the use of CAD is expanded to include FEA simulation. Close integration between CAD and FEA requires that FEA users are well familiar with CAD. Therefore, students already proficient in CAD benefit from not having to spend time on CAD specific issues common in FEA applications This opens up space for both more theory and for solving more advanced and applied problems which again better prepare studentsfor internships and for work in industry.
Since the third year FEA course covers both structural and thermal analyses as applied to mechanical components and to heat transfer problems it in only natural to link it to other third year courses such as Heat Transfer. Structural problems are studied in the Finite Element course along the applicable theory while thermal problems are illustrated with FEA in the Heat Transfer course. Further, the Finite Element course is linked to the Mechanical Components course by sharing assignments and analysis problems.

The third year Finite Element Analysis course leads to fourth year Mechanical Vibration which expands the use of FEA into the realm of vibration analysis. All courses also lead to the fourth year capstone design project. The map of courses linked so far is shown in figure 1. The authors consider progressive and well coordinated use of CAE analysis tools, a "mortar" in the course linking effort s.

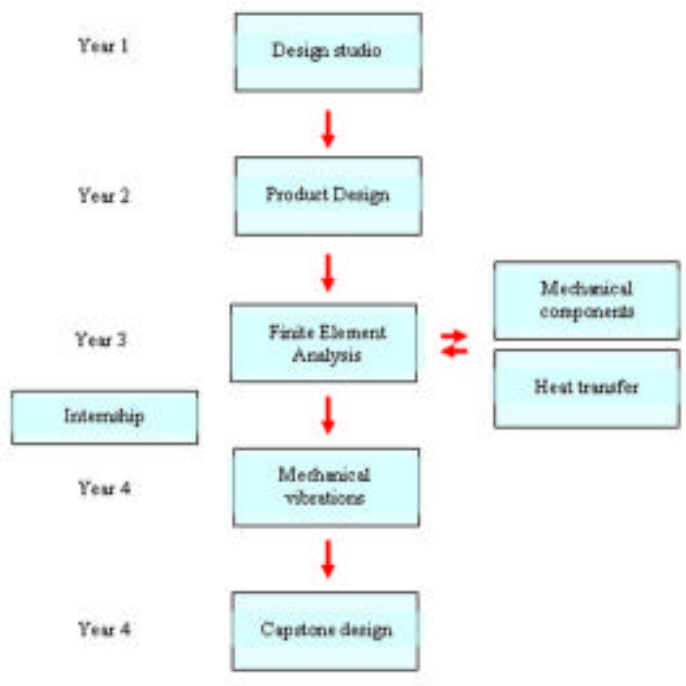

Figure 1: Courses linked in the Mechanical and Materials Engineering program.

\section{RESULTS}

Course linking efforts have been underway since the academic year $2007 / 2008$. Early results indicate improvements in the quality of the fourth year capstone design projects especially in the area of design documentation and FEA skills. These improvements are very difficult to quantify but have been recorded by interviewing supervisors of internship students' and sponsors of industrial capstone design projects. Students who have experienced the effects of course linking are now entering the labor market. Hopefully in the near future they will provide feedback on the effectiveness of this initiative.

\section{DISCUSSION}

Course linking is a collaborative effort which benefits have been recognized and discussed ${ }^{1,2}$. The quantitative assessment of its effectiveness and optimization of the implementation methods is a long term project. After preliminary results have confirmed the merits, the authors are now in the process of establishing measures that will be used in the future assessment of teaching effectiveness.

\section{REFERENCES}

1. Lengsfeld CS, Black J, Hightower N, Root M, Stevens K, Whitt M. J ASEE 2004, 79-85

2. McKenna AF, Yalvac B, Light G. J ASEE 2009 17-26 